DOI: $10.7242 / 2658-705 X / 2019.1 .5$

УДК 993.26

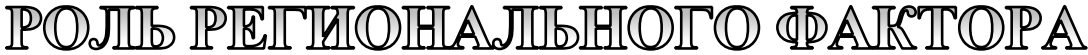

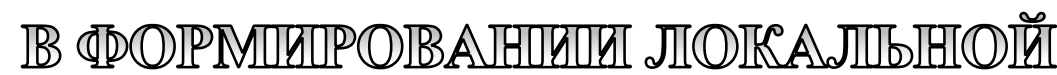

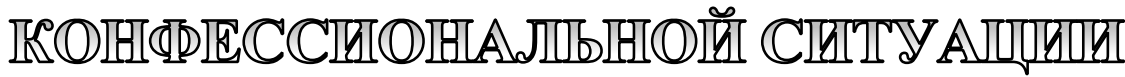

\section{С.В. Рязанова, Пермский федеральный исследовательский центр УрО РАН}

Региональная локальная ситуация рассматривается как явление комплексного характера, которое фрормируется под воздействием фракторов различной природы. Региональный ракурс изучения привлекается для анализа как наиболее продуктивный для верификации гипотез, учета деталей и специфических форм, отхода от шаблонов в восприятии религиозных френоменов. Компоненты религиозной картины региона трактуются как результат адаптации вероучительных положений к локальному историко-культурному контексту. Иерархия фракторов влияния может отличаться от региона к региону, но сама совокупность присутствует в любом кейсе, к которому применяется экспертный анализ. Регион определяется на основе формальных критериев, с учетом исторического и географического обоснования. Отбор фрактического материала для анализа осуществляется через определение понятия религии как инструментального. Анализ конфессиональной ситуации предполагает учет синхронного и диахронного аспектов в ее складывании и изменении. К базовым факторам влияния на религиозную картину региона относятся географические условия, в которых существует территория; интенсивность протекания глобализационных процессов в локальном варианте; этнический состав населения, специфика брачных стратегий, особенности экономической ситуации, символический облик территории. Учет наиболее значимых характеристик позволяет анализировать религиозные сообщества и межрелигиозные связи и реализовать прогностические функции социологии религии.

Ключевые слова: религия, религиозная ситуачия, регион, религиозные организащии, факторы влияния.

Исследователь локальной религиозной ситуации как никто другой способен оценить утверждение о том, что некая идеальная модель религии существует только на уровне богословских трудов и в границах созданных в кабинетах моделей. Религиозная ситуация, рассматриваемая как сложная и динамичная система, формируется и функционирует под влиянием совокупности факторов различного генезиса, неравноценно

влияющих на отдельные религиозные сообщества и целостную картину верований региона: «под определением религии всегда спрятаны гетерогенные, исторически обусловленные элементы» [14, с. 32]. Региональный ракурс изучения, как генерированный локальными традициями, менталитетом и дискурсивными практиками [15, с. 222], представляется продуктивным. В его границах существует больше возможностей для верификации 
гипотез, учета деталей и специфических форм, отхода от шаблонных схем, связанных с вестернизированным (научным) и/или теологическим определением идеальной религии. Анализ региональных вариантов верований позволяет отказаться от представления о религии как универсальной модели, если говорить о ее практическом воплощении.

В поле исследования попадают, разумеется, не зафиксированные на уровне ментальности учения, а совокупности верующих, являющихся акторами определенного набора социальных действий и сигнализирующих теми или иными способами о своей религиозности. При этом обязательно должна делаться поправка на адаптацию верующими любого учения, что может приводить к увеличению количества религиозных групп, чье существование инспирировано одной религиозной доктриной. Это означает, что аналитик имеет дело с тем, что антропологи и фольклористы традиционно называли «народной религией» $[4$, с. 69], обесценивая ее значение и формируя миф об эквивалентности догматической части религии, зафиксированной на уровне священных текстов и сопровождающей их литературы, и реальных механизмов воплощения и сценариев развертывания религиозной жизни, которые являются неотъемлемой частью социального пространства.

В рамках данного текста мы предлагаем определить иерархию факторов, определяющих складывание, развертывание и историческое существование конфессиональной ситуации в регионе, что позволит максимально точно выстроить исследовательские стратегии - от методологического подхода до прикладных методик. Аналитические процедуры будут осуществлены через вычленение сфер, генерирующих существенные для религиозной ситуации обстоятельства; выделение возможных локальных вариантов для действия каждого фактора; определение исследовательских границ и потенциала аналитики в условиях учета всей совокупности факторов на примере Прикамья как части Западного Урала.
Полем для анализа любой локальной конфессиональной ситуации становится территориально определенный регион, чаще всего - на основе формальных критериев (округ, край, республика и т.п.). Использование терминов «Средний Урал», «Поволжье», «черноземный регион» вносит дополнительные сложности в установление границ, требуя исторического и географического обоснования, что, впрочем, не означает невозможность реализации проекта в таких рамках. Важно иметь в виду, что конфессиональная картина на выбранной для исследования территории будет отображена более корректно при указании наличия набора религиозных сообществ в ее отдельных точках, а не на основе составления карт «распределения религий» в регионе. Специфика современной культурной ситуации такова, что только в исключительных случаях мы имеем дело с гомогенными в религиозном отношении районами, с четко фиксируемыми границами. Определение такого района как принадлежащего приверженцам определенного вероучения на основе мажоритарного принципа также представляется некорректным, поскольку для части религий (православие, ислам) не всегда представляется возможным выделить четкие критерии конфессиональной идентичности [подробнее см.: 6; 10]. Наличие некоторого числа верующих с синкретическими религиозными взглядами, а также не определившихся в этом отношении и небрежно отвечающих в ходе опроса, дискредитирует как полученную информацию, так и сделанные на основе ее выводы о конфессиональной структуре территориальной общности. Даже для харизматических церквей, члены которых четко идентифицируют свою принадлежность к определенной общине и вовлечены в культовую практику, все более характерным становится формальное участие в жизни церкви и периодический межконфессиональный транзит, под которым мы подразумеваем переход из одного религиозного сообщества в другое. Выводы количественного 
характера в таких условиях могут оказаться «скоропортящимися» и неспособными отразить динамику религиозной жизни. Предпочтительным поэтому представляется использование критериев качественного характера, основанных на констатации присутствия религиозной общности в социальном пространстве региона и указании на ее специфические черты. При этом необходимо перед началом сбора материала установить четкие рамки того, что будет отнесено к понятию религии в интересах релевантного отбора, вне зависимости от того, имеет ли то или иное сообщество официальный конфессиональный статус [4, с. 68].

Учет регионального фактора включает в себя синхронный и диахронный аспекты $[4$, с. 72], каждый из которых является значимым как для формирования конфессиональной картины, так и протекания процессов религиозной самоидентификации индивидов и групп в условиях внешне устоявшейся культурной ситуации. Поэтому предлагаемый далее расклад факторов, в идеале, должен быть проанализирован не только применительно к современности, но и в своеобразных «реперных точках» в истории, которые привели к принципиальным изменениям в религиозной ситуации или ее еще большей консервации. Тем самым более явственно определяются значимые для конфессионального пространства события.

Чаще всего религиозная ситуация региона рассматривается в синхронном ракурсе, предполагающем учет ее статической и динамической характеристик. Обе характеристики формируются под воздействием почти всех сфер общественной жизни, как бы внешне далеко они не отстояли от деятельности сообществ верующих. Поэтому при рассмотрении каждого из факторов стоит учитывать стабилизирующий компонент, обеспечивающий структурное сохранение религиозного континуума и трансформирующий сложившийся расклад групп и их взаимодействий.

Несомненно, к базовым факторам формирования локальной конфессиональ- ной ситуации следует относить географические условия, в которых находится регион. Напрямую на набор религиозных сообществ влияет расположение территории, прежде всего, связанное с возможностью для давно существующих групп верующих контактировать с инаковерующими сообществами, при необходимости передвигаться за пределы региона или, наоборот, занять охранительную в мировоззренческом плане позицию, минимизируя контакты. Именно последний вариант был реализован в свое время в социальных стратегиях старообрядческих сообществ, уходивших от преследований на Урал и в Сибирь.

В настоящее время, в условиях развития коммуникационных технологий и улучшения проходимости транспортных средств, полный уход от современности становится все более проблематичным, но по-прежнему реализуется точечно отдельными сообществами верующих. В свою очередь, регион, расположенный в узлах транспортных коммуникаций, в большей мере обречен на изменения конфессиональной ситуации разного масштаба, поскольку предоставляет возможность как для появления новых сегментов религиозного сообщества на местах, так и их достаточно быстрого исчезновения.

Для Пермского края, являющегося транзитной территорией для потоков внутрироссийской миграции, примером, доказавшим, что конфессиональная картина Прикамья может быть динамичной в некоторой ее части, стало кратковременное (немногим больше полугода) пребывание на севере региона общины последователей бывшего архиепископа Чукотского и Анадырского Диомида. Опасаясь преследований со стороны РПЦ МП, они некоторое время находились в Тульской области, потом через Костромскую область переместились в Чердынский район Пермского края, рассчитывая создать там закрытое для внешних посетителей поселение. Представители группы выдвинули жесткие условия, предполагающие минимальный контакт с властями, угрожая, в противном случае, начать убивать детей в общине. 
Неприятная ситуация разрешилась благодаря уральскому климату: приверженцы Диомида осознали всю сложность зимовки в условиях плохого снабжения, отсутствия отопительных ресурсов, приемлемых зимних дорог и предложили руководству края компромисс: община принимает гуманитарную помощь, но при первой возможности покидает территорию края, что и было вскоре осуществлено.

Не столь яркий, но показательный случай представляют собой передвижения внутрироссийских мигрантов-мусульман по территории Урала и Сибири. Находящийся на пути транзитных потоков регион может не обладать привлекательностью для желающих постоянно проживать или ищущих высокие заработки, но сам статус своеобразного перевалочного пункта способствует поддержанию численности и функционированию широкого спектра мусульманских диаспор, стремящихся влиять на управление местной умой и, в некоторых случаях, корректировать сложившиеся традиции религиозного поведения. Для Прикамья, с его небольшой, но постоянной убылью числа мигрантов, привычным стало не только их активное участие в наиболее популярных религиозных праздниках и обучение в двух мусульманских колледжах, но и предложения по изменению порядка намаза и даже конструктивных особенностей Соборной мечети в краевом центре [7, с. 84-87].

Особая ситуация может возникнуть в условиях пограничного по отношению ко всей территории страны положения региона либо его экстерриториального статуса. Первый потенциально обеспечивает большую интенсивность контактов с иностранными верующими, носителями других вариантов уже привычных и новых учений, а второй, с одной стороны, может послужить мобилизующим фактором для сохранения существующих общин, одновременно затрудняя - если такие существуют - связи с центральными организациями. Впрочем, обе ситуации в условиях современных глобализационных процессов и очередной волны технических нововведений сохраня- ют все меньший потенциал коррекции конфессиональной картины региона.

Несомненно, оказывает влияние на состав вероучительных систем и то, что можно определить как этнический субстрат. Несмотря на то, что религиозный выбор не связан напрямую с национальной принадлежностью, ряд обстоятельств исторического и психологического характера позволяет вычленить ряд зависимостей между этнической и религиозной идентичностью. Прежде всего, существует ряд религиозных систем, традиционно исповедуемых определенными этносами. Принадлежность к этим религиям не является обязательной, но среди представителей данного народа и в настоящее время встречается чаще, будучи обусловленной стереотипами массового сознания и полным отождествлением наиболее распространенного верования с традиционной культурой. Поэтому в обыденном сознании и представителя данного этноса, и окружающих происходит сращивание этнической и религиозной принадлежности, в крайних случаях приводя к утверждениям о неприемлемости другого вероисповедания. Именно благодаря такому сращиванию поверхностный взгляд на карту расселения народов по территории региона позволяет вычленять своеобразные религиозные «анклавы» (допустим, указывать, что Ордынский, Бардымский, Чернушинский и Октябрьский районы Пермского края являются местами компактного проживания мусульман). На наш взгляд, выделение таких компактных сообществ постепенно уходит в прошлое в силу практики дисперсного расселения представителей различных национальностей на территории страны и ее отдельных субъектов.

Однако такой подход и сам по себе имеет значительный дефект: срастание религиозных традиций с общекультурными оборачиваются, как правило, так называемой «стертой», неактивной религиозностью. Большинство ее носителей обращается к религии в двух случаях в ситуации экзистенциального кризиса любого генезиса (тяжелая болезнь, смерть близкого, необходимость решить 
сложную задачу и др.) и при участии в массовых опросах. В обоих случаях процесс религиозной самоидентификации осуществляется в очень короткий промежуток времени, не позволяющий сделать осознанный выбор. В условиях дефицита рационального мышления предпочтение отдается стереотипному восприятию и эмоциональным решениям, дополненным невысоким уровнем грамотности в вопросе существующих религий. Итогом становится высокий процент выбора так называемых «традиционных» религий, имеющий очень слабую связь с реальной воцерковленностью (соблюдением соответствующих предписаний) и информированностью в отношении религиозного учения и культовой практики.

Неактуальность религиозной самоидентификации респондентов ставит вопрос о принципиальной возможности установления границ генеральной совокупности, необходимых для использования количественных методов. Ситуация усугубляется проблемой доверия респонденту, поскольку, по нашему мнению, необходимость отвечать на «неинтересные» вопросы с большой вероятностью влечет за собой небрежный ответ, позволяющий этот вопрос просто снять.

Дополнительным обстоятельством, способствующим выведению религиозного самоопределения и сферы актуальных мировоззренческих задач, становятся межэтнические браки, итогом которых может быть и изменение религиозной принадлежности (очень распространенный вариант в случаях заключения брака жительниц Российской Федерации с мигрантами-мусульманами), и ее своеобразное снятие. Приходится признать, что этничность как фактор может быть учтена, но имеет все меньшее значение в условиях учета как количественной, так и качественной конфессиональной картины региона. Даже верования мифологического характера, безусловно закрепленные в локальных сообществах, постепенно размываются и корректируются благодаря влиянию религиозной и светской куль- тур. Распространение новых религиозных движений, не имеющих корреляции с этничностью, не позволяет делать однозначные выводы и прогнозы о распространении того или иного вероучения. Исключением в этом случае, на наш взгляд, являются регионы с «активным», актуальным исповедованием ислама (северный Кавказ), где соблюдение религиозных норм не только закреплено в традиции, но и до настоящего времени входит в набор общественных императивов.

Несомненно, значимой для складывания и развития картины верований региона является экономическая ситуация. Особенности развития экономики не способны, по нашему мнению, напрямую корректировать долю той или иной религии в локальном пространстве, но обладают потенциалом стимулирования конфессиональной ситуации, связанного с увеличением либо уменьшением религиозного многообразия. Статус региона-донора по отношению к федеральному бюджету, высокий уровень средней заработной платы, наличие рабочих мест инициируют усиление внутренних и внешних миграционных потоков. Прибывшие на работу субъекты необязательно являются носителями ярко выраженной религиозности, но, в ряде случаев, они способны создавать даже своеобразные религиозные анклавы, в границах которых реализуются иные, по сравнению с принимающей территорией, принципы отношения к священному и выстраивания стратегий социального поведения.

В наибольшей мере это пока касается уже упомянутых представителей мусульманского сообщества, поскольку носители других вероисповеданий либо составляют количественно незначительные объединения, либо не дают повода специально обращать на себя внимание. Мусульмане, как являющиеся гражданами страны, так и приезжающие из-за ее пределов, имеют высокий уровень внутригрупповой солидарности и знакомства с религиозными нормами. Они ориентированы на активное участие в религиозных событиях и околорелигиозной деятельности (мате- 
риальное обслуживание ритуальных практик, торговля предметами религиозного обихода и продуктами, соответствующими требованиям культа и др.), имеют ярко выраженную позицию в мировоззренческих и социальных вопросах. Совокупность этих характеристик способна вызывать к жизни целый спектр культурных феноменов, новых для принимающего региона [13, с. 380-382]. К таковым относятся возникновение новых мест массового поклонения (в Перми - это молельное помещение на 400 человек на одной из окраин города); активное, по сравнению с местными верующими, участие в постройке зданий культового назначения и их благоустройстве (реставрация Соборной мечети, постройка столовой и здания для курсов, основной объем пожертвований на крупные религиозные праздники, финансирование и работа на строительстве новой мечети в Пермском крае обеспечиваются пожертвованиями мигрантов); более тщательное соблюдение норм религиозной жизни.

Хотя в настоящее время мусульманские сообщества не составляют большинства даже в местах традиционного проживания исповедующих ислам, их активная религиозная позиция, сопровождающаяся вовлечением неофитов (русские жены гастарбайтеров из Центральной Азии, мусульмане славянского происхождения), позволяет говорить о значимости этого фактора в конфессиональной картине региона, а следовательно, и о важности экономической составляющей в ее складывании.

Не стоит сбрасывать со счетов и тот факт, что экономически благополучный регион, привлекающий к себе внимание представителей небольших религиозных групп, в большей мере будет характеризоваться конфессиональным многообразием, чем территории, находящиеся в состоянии инвестиционно-финансового упадка. Небольшие общины верующих сами по себе не трансформируют региональную картину верований, но формируют варианты религиозной альтернативы, востребованные частью верующих в со- временной культуре. Активность деятельности этих групп напрямую зависит от регионального политического режима, позиция которого по отношению к отдельным сообществам верующих также определяет логику взаимодействия религиозных сообществ между собой и с внешним миром. Местные власти помимо поддерживания политических трендов, характерных для страны в целом, создают прецеденты неофициальной поддержки некоторых исторически закрепленных религиозных организаций, а также используют возможности манипулирования общинами верующих за счет административной помощи одним и игнорировании либо третировании других. Это провоцирует, в ряде случаев, напряженные отношения между религиозными сообществами [7, с. 84-87], выдавливание части конфессий из публичной жизни (примером чего может служить жесткий отбор участников в Межконфессиональный консультативный комитет в Перми).

К общекультурным факторам формирования конфессиональной ситуации, не имеющим прямой связи с автохтонной традицией, стоит отнести социальный статус региона, связанный с его символической нагрузкой. Речь идет о наборе мифологем, сформировавшемся в ходе исторического развития территории и инспирирующем привлечение внимания со стороны представителей так называемых нетрадиционных религий. Эти мифологемы могут быть связаны как с дохристианским культурным наследием, необязательно сохранившемся в виде достоверных образов и сюжетов, так и событиями, периодически выделявшими регион на фоне других территорий.

Применительно к Прикамью и Пермскому краю как административно-территориальной единице представляется возможным вычленить несколько слоев региональных мифов, стимулирующих приток новых религиозных общин. К первому относятся трансформированные обыденным религиозным и мифологическим сознанием предания о чуди, ушедшей под землю 
с приходом русских переселенцев $[2 ; 3]$ и элементы религиозной мифологии, на которую оказал влияние историко-культурный контекст региона $[11 ; 12]$. В качестве второго слоя выступают мифологии, сложившиеся в эпоху предреволюционной модернизации региона, связанные не только с адаптацией православия к местным условиям, но и с формированием особых сфер жизнедеятельности (например, горнозаводских поселков, внутри которых формировались мифологемы со специфической сюжетикой) [9]. Третий слой представлен современной бытовой мифологией, в ряде случаев формирующей сюжеты, выходящие за пределы профанной жизни. Для Прикамья таким мифом, получившим широкое распространение, стал современный фольклор о поселке Молебка, якобы ставшем местом приземления инопланетян.

Совокупность мифологических сюжетов вызвала возникновение представлений об Урале (и Прикамье как его части) как исключительном месте, которое является родиной пророков (в частности, Зороастра, выводимого некоторыми представителями школы Павла Глобы с Южного Урала), будет спасено при переходе в новое измерение [5, с. 110123], станет основой для появления новой расы людей и деятельности пророков [1, с. 64-68]. Популяризация этих идей в среде так называемых религиозных «ищущих» (англ. seeker) спровоцировала привлекательности территории для представителей большого числа мистических и околорелигиозных движений, по количеству которых Пермь догоняет столичные города.

Обозначенная совокупность факторов не является исчерпывающей, но по своей значимости занимает первостепенные позиции в формировании конфессиональной картины региона, а также протекающих религиозных процессов [8, с. 27-31]. Учет этих характеристик не только помогает адекватно анализировать существующие религиозные сообщества и сложившиеся между ними социальные связи, но и позволяет реализовать прогностические функции социологии религии. Представляется, что иерархия факторов может меняться от региона к региону, но сами факторы как значимые в любом случае будут оказывать определенное влияние. Все они служат подтверждением невозможности рассмотрения явлений и процессов в религиозной сфере общественной жизни как обусловленных исключительно внутренними характеристиками.

Библиографический список

1. Афанасенко Я.А. Социально-философский анализ становления новой религии: дис... канд. филос. наук. - Пермь, 2000. - 172 с.

2. Лепихин А.Н. Памятники археологии в современном фольклоре // Пермское Прикамье в истории Урала и России: материалы Всерос. науч.-практ. конф. - Березники, 2000. - С. 58-62.

3. Лепихин А.Н., Рязанова С.В. Хтонические персонажи в уральской мифологии // Там же. - С. 65-69.

4. Панченко A.A. Христовщина и скопчество: Фольклор и традиционная культура русских мистических сект. - 2-е изд. - М.: ОГИ, 2004. - С. 69.

5. Рязанова С.В. Архаические мифологемы в политическом пространстве современности. - Пермь: Перм. гос. ун-т, 2009. -238 с.

6. Рязанова С.В. «Вот люди-то там стоят, а ты не можешь»: посещение церкви в современном пермском православном сообществе. - Пермь: ПГИК, 2018. - 172 с.

7. Рязанова С.В. «Два ислама» в Пермском крае: истинный и мнимый конфликты // Этнорелигиозная конфликтология. - 2011. - № 1. - С. 78-87.

8. Рязанова C.B. Religious conflict as non-religious: form, content, structure // Ученые записки Забайкальского гос. ун-та. Сер.: Философия, социология, культурология, социальная работа. - 2016. T. 11. - № 3. - C. 26-32.

9. Рязанова С.B. Трансформация христианства в образах горнозаводской мифологии // Пермское Прикамье в истории Урала и России: Материалы Всерос. науч.-практ. конф. - Березники, 2000. - С. 69-72.

10. Рязанова C.B., Михалева А.B. Феномен женской религиозности в постсоветском пространстве (региональный срез). - Пермь: изд-во ПГУ, 2011. - 255 с. 
11. Рязанова C.B., Федотова М.A. Трансформация христианства: хтонические элементы в уральском варианте православного мифотворчества // Пермское Прикамье в истории Урала и России: Материалы Всерос. науч.-практ. конф. - Березники, 2000. - С. 62-65.

12. Рязанова C.B., Федотова М.A. Трансформация христианства на Урале // Христианство и грядущие судьбы России: материалы науч. конф. - Пермь, 2000. - С. 78-81.

13. Рязанова C.B., Черных A.B. Миграционные процессы в среде мусульман как фактор формирования конфессиональной картины региона (на примере Урало-Поволжья) // Научный ежегодник Института философии и права УрО РАН. - Екатеринбург, 2012. - С. 379-382.

14. Asad T. The Construction of Religion as an Anthropological Category // Asad T. Genealogies of Religion. Discipline and Reason of Power in Christianity and Islam // The Hopknis University Press: London. Baltimore, 1993, - P. 27-55.

15. Kippenberg H.G. Religious History, Displaced by Modernity // Numen. - Vol. 47. No. 3, Religions in the Disenchanted World, 2000. - P. 221-243.

\title{
THE ROLE OF THE REGIONAL FACTOR DETERMINING THE LOCAL RELIGIOUS SITUATION
}

\author{
S.V. Ryazanova \\ Perm Federal Research Centre UB RAS
}

The regional local situation is considered to be a complex phenomenon shaped under the influence of various factors. The study uses the regional aspect for the analysis as the most effective way to verify hypotheses, to take the details and specific forms into account and to escape stereotypes when perceiving religious phenomena. The components of the religious panorama of the region are regarded as a result of doctrines adaptation for the local historical and cultural context. The hierarchy of influential factors may vary from one region to another, but the set of factors is presented in any case the expert analysis is applied to. The region is defined on the basis of formal criteria considering historical and geographical background. The selection of factual material for further analysis is carried out through defining the concept of religion as an instrumental one. The analysis of the confessional situation implies taking into account synchronous and historical aspects of its formation and change. Basic factors that influence the religious panorama of the region include the existing geographical conditions of the territory; the intensity of globalization processes in their local variation; the ethnic structure of the population, the specific character of mating strategy, the peculiarities of economic situation and the symbolic image of the territory. The most significant characteristics to be taken into account enable to analyze religious communities and interreligious relations, as well as to apply the predictive functions of the sociology of religion.

Keywords: religion, a religious situation, region, religious organizations, influential factors.

\section{Сведения об авторе}

Рязанова Светлана Владимировна, доктор философских наук, доцент, ведущий научный сотрудник, Пермский федеральный исследовательский центр УрО РАН (ПФИЦ УрО РАН), 614900, г. Пермь, ул. Ленина, 13A; e-mail: svet-ryazanova@yandex.ru 